\title{
ADAPTIVE CONTROL OF BULLDOZER'S WORKFLOWS
}

\author{
Alexej Bulgakov ${ }^{1 *}$, Sergei Emelianov ${ }^{1}$, Thomas Bock ${ }^{2}$, and Georgy Tokmakov ${ }^{3}$ \\ ${ }^{1}$ South West State University, Kursk, Russia \\ ${ }^{2}$ Technical University of Munich, Germany \\ ${ }^{3}$ South Russian State Technical University, Novocherkassk, Russia \\ * Corresponding author (a.bulgakow@gmx.de)
}

\section{ABSTRACT}

The most important task for bulldozer's traction mode control is to use its traction capacity in full by means of its end-effectors control. To keep traction mode at maximum or at a given resistance value applied to end-effectors automatically is difficult due to a great number of stochastic factors affecting the bulldozer. Bulldozer is taken as a mechatronic system $[1,2]$. The study presents analytic dependences for the sub-processes where analytic modeling based on bulldozer's parameters correlation knowledge is applicable. Models of the sub-processes are included into the general structure of bulldozer's workflow simulation model.

Simulation technique is demonstrated through model development of the bulldozer as a universal machine operating in modes of soil movement and subgrade surfacing.

In developing the models mathematical apparatus of the theory of random processes, transfer functions, table interpolation, numerical solution of algebraic equations and ordinary differential equations in the Cauchy form was used.

A dynamic model of the drawing prism formation was developed describing the dependence of the volume of prism on the variable digging depth and variable bulldozer speed. A general structure of the model of bulldozer's workflows due to the working process control objectives was developed.

\section{KEYWORDS}

Robotics and mechatronics, Automation and control, Bulldozer, Neural network technologies.

\section{INTRODUCTION}

Bulldozers equipped with modern navigation and information systems are mobile mechatronic objects, and they can be integrated into general process of intellectual construction [3]. The integration will provide optimal efficiency of the construction cycle and will ensure lean production process [4,5].
On the basis of bulldozer's workflow dynamics modeling and analyses described in a variety of works, we have concluded that the models to describe kinematics and dynamics of its working equipment, hydraulic and transmission features tend to be analytical formulas derived from well-known laws of physics and from information on bulldozer's structure and mechanisms. If some parameters of the workflow are unknown or constantly changing, the models are either statistical tables or empiric dependences summarizing experimental data. The models depict interaction of end-effectors, engines and environment as well as statistic features of bulldozer's complex units.

Application of regulators based on classical control theory is difficult due to the frequent changes in workflow conditions. Thus, it is necessary to develop adapted control systems to eliminate the difficulties described. The system includes both the bulldozer's dynamics modeling and bulldozer's workflow control method to take into consideration the complex nonlinear dependencies between workflow parameters and incomplete information on its working conditions changes.

Having reviewed adaptive and intellectual control methods $[6,7]$, we propose to create an adaptive control system for technological processes to increase efficiency of bulldozer's control in comparison with traditional control methods.

\section{MOBILE MECHATRONIC OBJECT MATHEMATICAL DESCRIPTION TO PERFORM EXCAVATION WORKS ON THE BASIS OF A DOZER}

When researching a dozer's working process usually a number of design schemes are considered straight line, thread milling, wedge and exponential cutting. Meanwhile, a dozer moves along the surface that is formed by its blade. Therefore, when driving onto any surface roughness resulting from the dozer blade control or the change in its position due to any reason, causes position changes of the machine frame and along with the cutting edge that is any face deviation from a straight line in some extent is copied by the dozer. 
Observations $[1,2]$ show that quite often while designing a face its roughness is progressing, reaching a size at which the control over the workflow is lost. In this case, the operator has to align the face deliberately, trying to ensure its "tranquil" profile that allows doing excavation works smoothly, without frequent control system switching and reducing the dozer's operating speed that causes a slowdown and shows inferiorities of the blade control system. Obviously, if the control system operates in the antiphase towards deviations of the tractor frame with sufficient accuracy, the initial face roughness will not evolve and will be gradually cut. One of the most likely causes of the opposite phenomenon observed in practice, is the disparity between the velocity of the dozer $\mathrm{V}_{\mathrm{p}}$ and actual conveying speed of the working body $\mathrm{V}_{\mathrm{ot}}$ required in certain areas $\mathrm{Si}$ of the digging operating cycle, where $\mathrm{i}$ - is the number of the speed change $V_{o t}$. Speed ratio depends on the dozer's geometrical dimensions (Figure 1) and its control system.

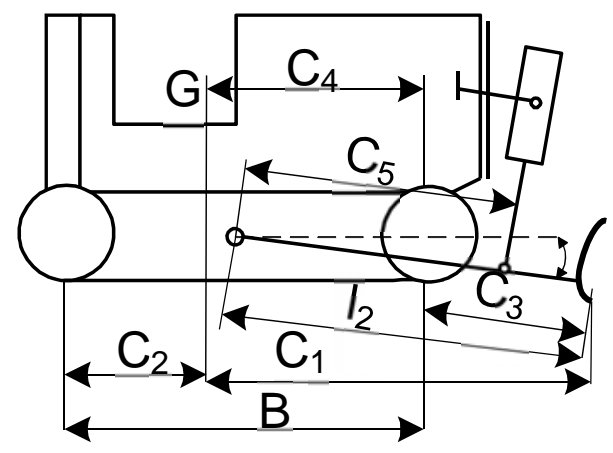

Figure 1 Dozer's geometrical dimensions

Mathematical model of the dozer's movement on a straight line tracking (frame alignment) is built using the Lagrange equations of the 2nd kind, under the assumption that the contribution to the dynamics of the drive gears and a track is small, compared with the contribution of the remaining parts of the dozer[8,9].

At the beginning of digging (Figure 2), the frame of the tractor makes a strictly forward movement over a distance of $\mathrm{S}_{1}+\mathrm{S}_{2}$ without hesitation relatively its mass center. The blade cutting edge in the area $\mathrm{S}_{1}$ dives into the soil to a depth equal to a predetermined cutting thickness $h$. Thus, the control action $a_{1}$ may be determined by the formula:

$$
\mathrm{a}_{1}=\frac{30 \mathrm{i}_{\mathrm{tr}} \mathrm{m}_{2}}{\pi \mathrm{r}_{\mathrm{k}} \mathrm{F}_{\mathrm{z}} \mathrm{i}_{\mathrm{pr}} \mathrm{C}_{5} \mathrm{n}}
$$

where $i_{t r}, i_{p r}$ - tractor transmission and hydraulic pump ratios;

$n$ - number of hydraulic cylinders;

$m$ - fluid mass in the hydraulic cylinders.

In the area $S_{2}$ the movement is made with $a_{2}=0$ until the mass center of the tractor won't move to the buttomhole edge.
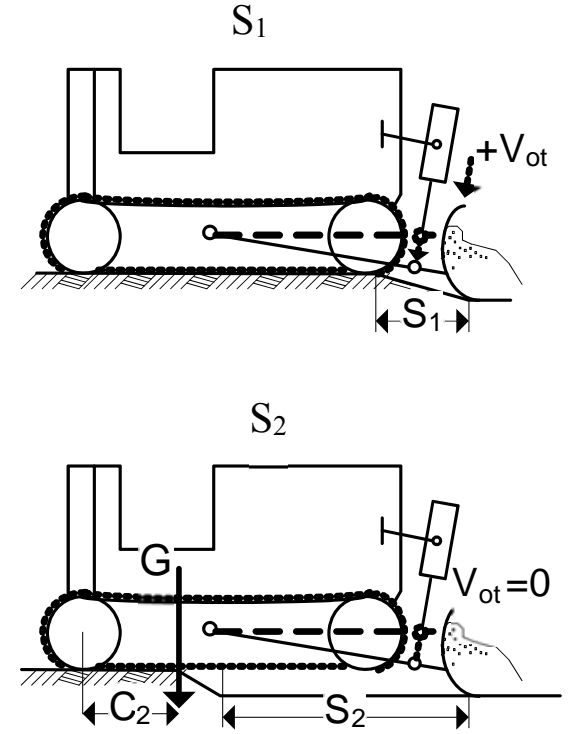

Figure 2. The movement of the tractor frame the beginning of digging.

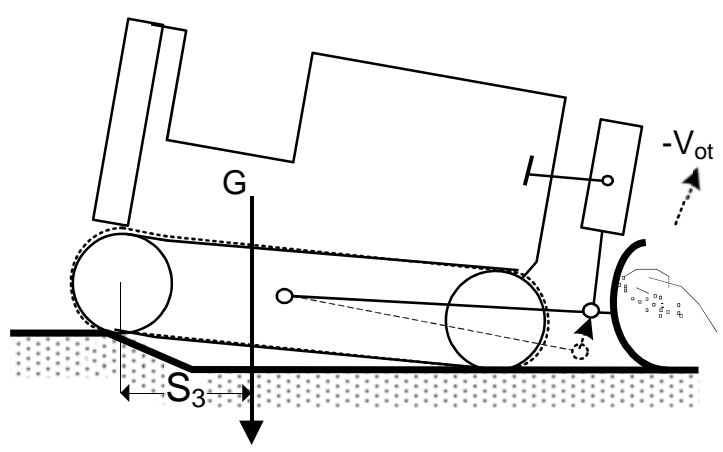

Figure 3 "Dives" in the drawn buttonhole

On further movement the dozer "dives" in the drawn buttonhole (Figure 3), so in the area $S_{3}$ it is necessary to lift the blade at a rate of $V_{o t}$, determined by the coefficient $\mathrm{a}_{3}$ :

$$
a_{3}=\operatorname{tg} \beta\left[e^{\frac{a V_{n} t}{C_{1}+V_{n} t}}\left(1+\frac{a C_{1}}{C_{1}+V_{n} t}\right)-1\right] \text {; }
$$

The area $\mathrm{S}_{3}$ ends after the dozer's back gear hits the edge of the face and reverse alignment of tractor frame starts. Length of the alignment area is $\mathrm{S}_{4} \approx \mathrm{S}_{1}$. Obviously, during this period it is necessary to start dropping the blade. The $\mathrm{a}_{4}$ determines the rate of dropping the blade in the given area:

$$
a_{4}=\frac{C_{3} S_{1}}{\left(C_{4}+S_{3}+V_{n} t\right)^{2}}
$$

To implement control actions $a_{i}=f\left(S_{i}, t, h\right)$ the dozer must be equipped with a vertical blade control system. 


\section{GENERAL STRUCTURE OF BULLDOZER WORKING PROCESS MODEL}

The main goals for analytic simulation modeling of bulldozer workflow are [1.2]:

- Bulldozer simulation as a controlled object to realize bulldozer's workflow parameters for using them at workflow neural network identification;

- Efficient traction modes parameters definition to be supported by the control system;

Simulation tasks:

- To single out the main sub-systems in bulldozer's structure and interrelations between the sub-systems;

- To develop analytic and simulation models for workflow elements and to include them into the general structure of the model.

The structure meets the goals of workflow control. When moving soil by the bulldozer, it is necessary to utilize bulldozer's traction capacity in full keeping the nominal traction value; when surfacing, the altitudes of the right and left side of the blade are to correspond the design marks. The key element at the scheme (Figure 4) shows the choice for the first or the second operational mode.

At developing the models, we use mathematical apparatus of the random processes theory, transfer functions, table interpolation, numerical solution of algebraic equations and ordinary differential equations in the Cauchy form. Random changes in the coordinates of untreated soil surface, as well as normalized fluctuations in the resistance forces on the working organ, caused by the heterogeneity of the soil are highlighted among the disturbing effects on the working organ of the bulldozer from soil conditions. Disturbance cause unwanted vertical movement of the working organ that affects both the coordinates and the change in the digging depth. Dependence of the blade position and dig depth from disturbances reflects the intricate relationship between the geometric parameters of the bulldozer in space. Loading conditions on the working organ are due to random variation in the dig depth and heterogeneity of soil properties. Soil digging process with bulldozer working organ is studied on the base of the finite element model of the soil mass, a mathematical model of random forces of resistance on the working organ being developed. The actual bulldozer velocity depends on the strength and the properties of the mover, transmission and the power unit. In its turn, disturbance parameters, movement of the working organ and the formation of stress depend on the velocity. Bulldozer drive model and mover interaction with the soil include engine model, mechanical and hydro mechanical transmission, as well as slipping. Control system regulator depending on the objectives, control algorithm and the incoming data from the bulldozer as a control object produces electrical signals to the electro- hydraulic distributors being part of the working organ hydro drive. Lifting or burying the blade is done to control either the pulling power, or the blade coordinates.

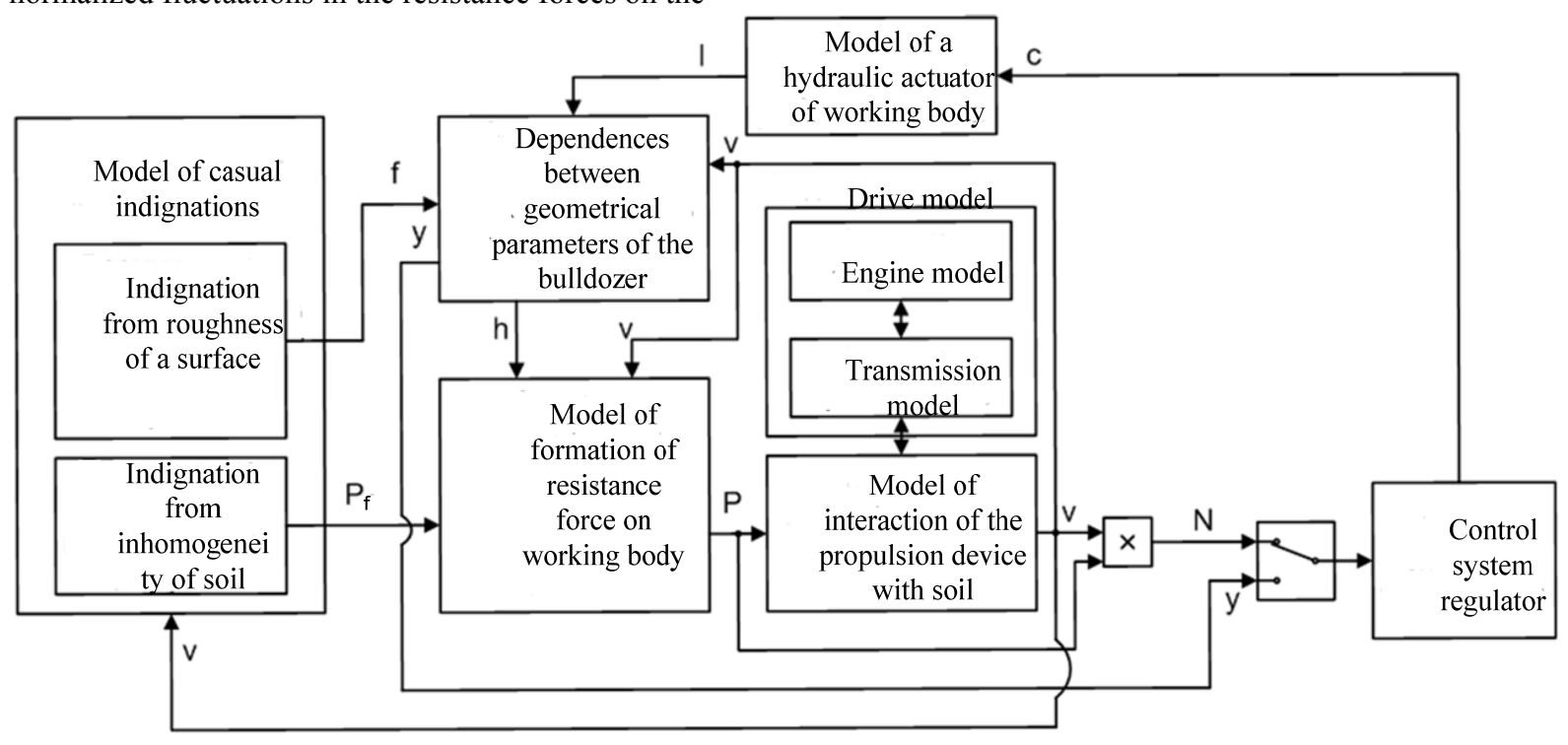

Figure 4. General structure of bulldozer working process model

\section{NEURO-FUZZY CONTROL OF BULLDOZER'S WORKFLOWS}

Applying a hybrid neural network consisting of a combination of traditional neural networks and neural networks of higher order (Figure 5). Thus, the neural network has the ability to switch between linear 
connections and connections of high order that can be described by the following dependencies [10-12].

Linear coupling:

High order coupling:

$$
y_{i}=\sum\left(w_{i j} x_{i}+b_{j 0}\right)
$$

$$
y_{i}=f\left(\prod x_{i}^{p_{i j}} * 1^{b_{j 0}}\right)
$$

Activation function:

$$
\mathrm{f}(\mathrm{x})=\frac{1}{1+\mathrm{e}^{-\mathrm{ax}}}
$$

where $\mathrm{w}_{\mathrm{ij}}$ - coupling weight coefficients; $\mathrm{y}_{\mathrm{i}}$ - output neuron signal; $\mathrm{x}_{\mathrm{i}}-$ input neuron signal.
Fuzzification procedure

Hidden layers

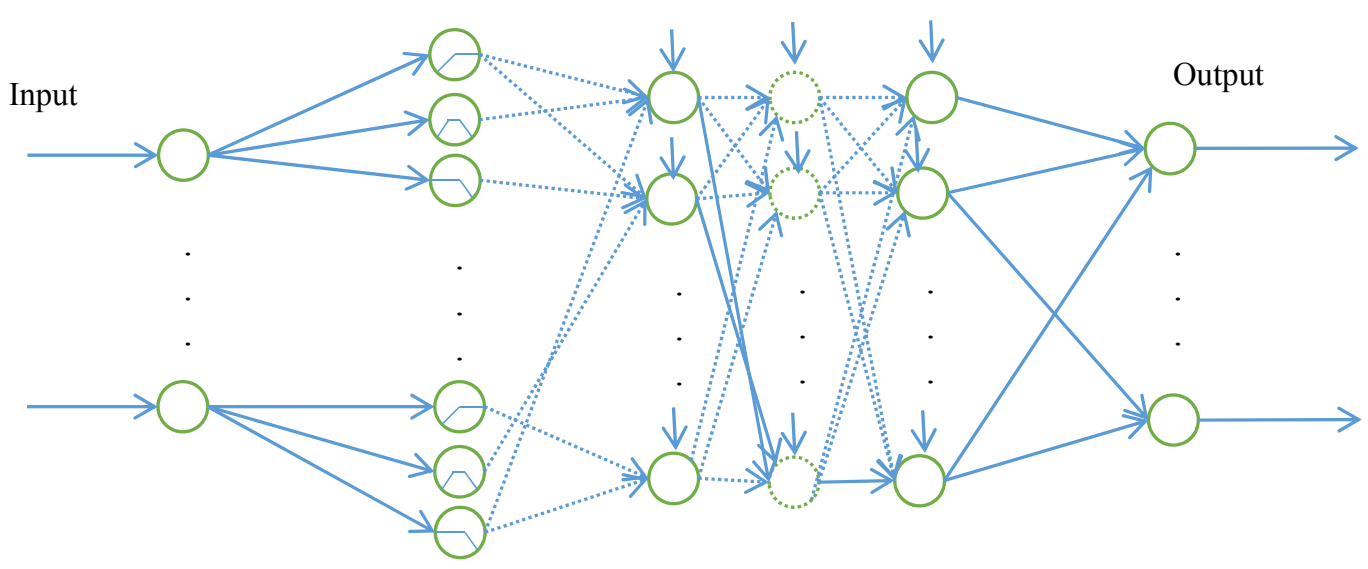

Figure 5. Hybrid Neural Network Structure

This implies that each layer depending on the operating mode may change the type of connection between neurons. For example, for a neural network consisting of 3 layers, the following options are possible (linear - L, higher order - HO): L-L; L-HO; $\mathrm{HO}-\mathrm{L}$ and $\mathrm{HO}-\mathrm{HO}$.

To optimize the created neural network is possible with the help of the genetic algorithm adaptation [1315] (Figure 6).

It is a method of random search with elements of adaptation, which is based on principles similar to the Darwin's evolution process of biological organisms. In this case, three types of operations are performed: crossing, mutation, selection. The fitness degree (how the population corresponds to the given task) is defined through the fitness function that can also include penalty functions for violation of additional restrictions on variable variables. There are various forms of crossing [16]. They make a selection of the fittest specimen, which constitute a parental pair and the crisscrossing of the chromosomal chains takes place, i.e. the descendant line code inherits fragments of codes of parental chromosomes. The mutation operator produces a local change in the line code of chromosomes with a given probability, which is one of the configurable parameters of the genetic algorithm $[17,18]$.

The selection operator allows creating a new population from a set of specimen, generated and modified descendants of specimen after mutation. The genetic algorithm is used to adjust the membership functions that are defined within the accuracy of a few changeable parameters, such as triangular, trapezoidal, radial functions. When simultaneously configuring several membership functions, the parameters of each of them are coded by their own segment of the chromosome, so that during the process of crossing the code sharing occurs only between chromosome segments of the same type. To configure a rule base to a specific chromosome fragment, some variant of the rule base is corresponded and in accordance with the accepted coding the choice of the genetic operators' type is performed. Thus, the architecture of the management and control system can be represented as follows (Figure 7): 


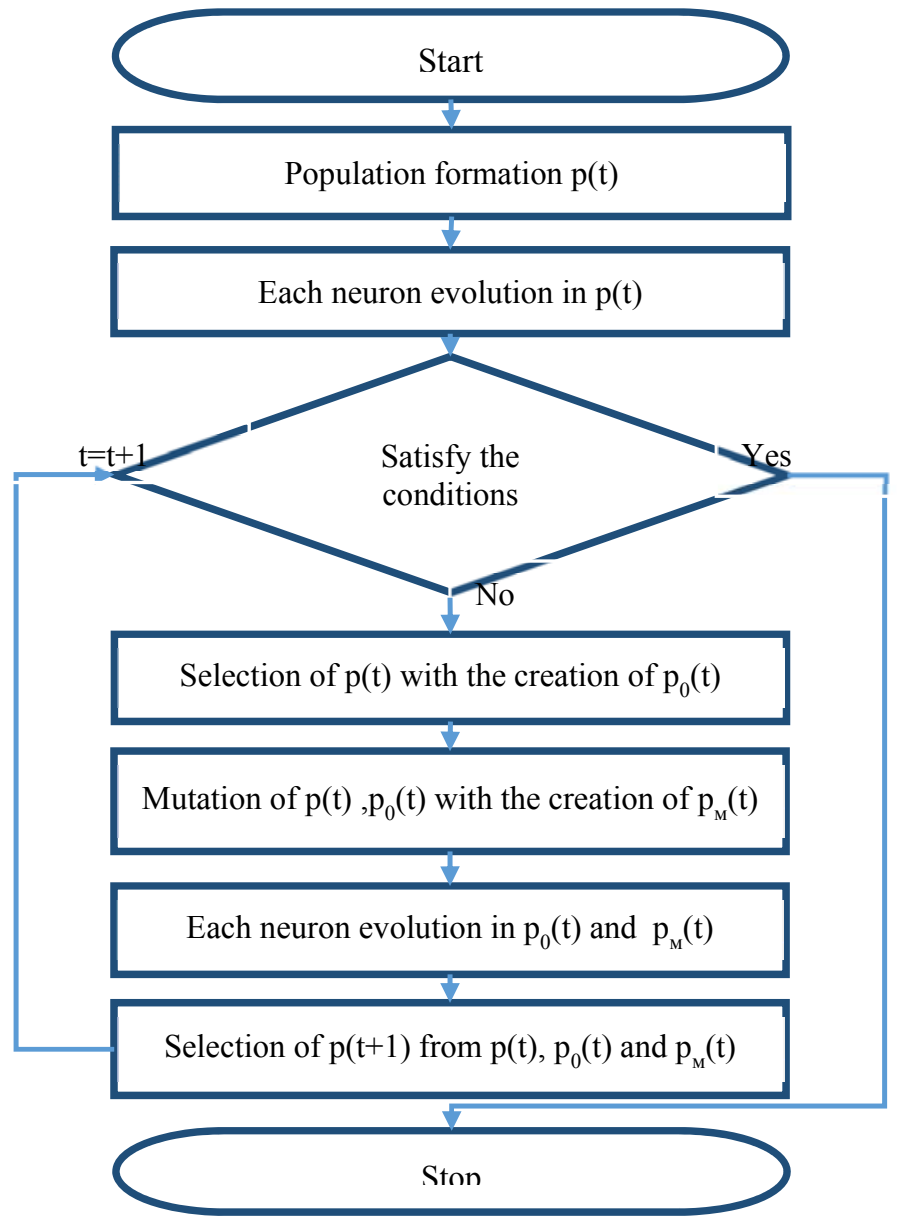

Figure 6. Hybrid neural network optimization algorithm

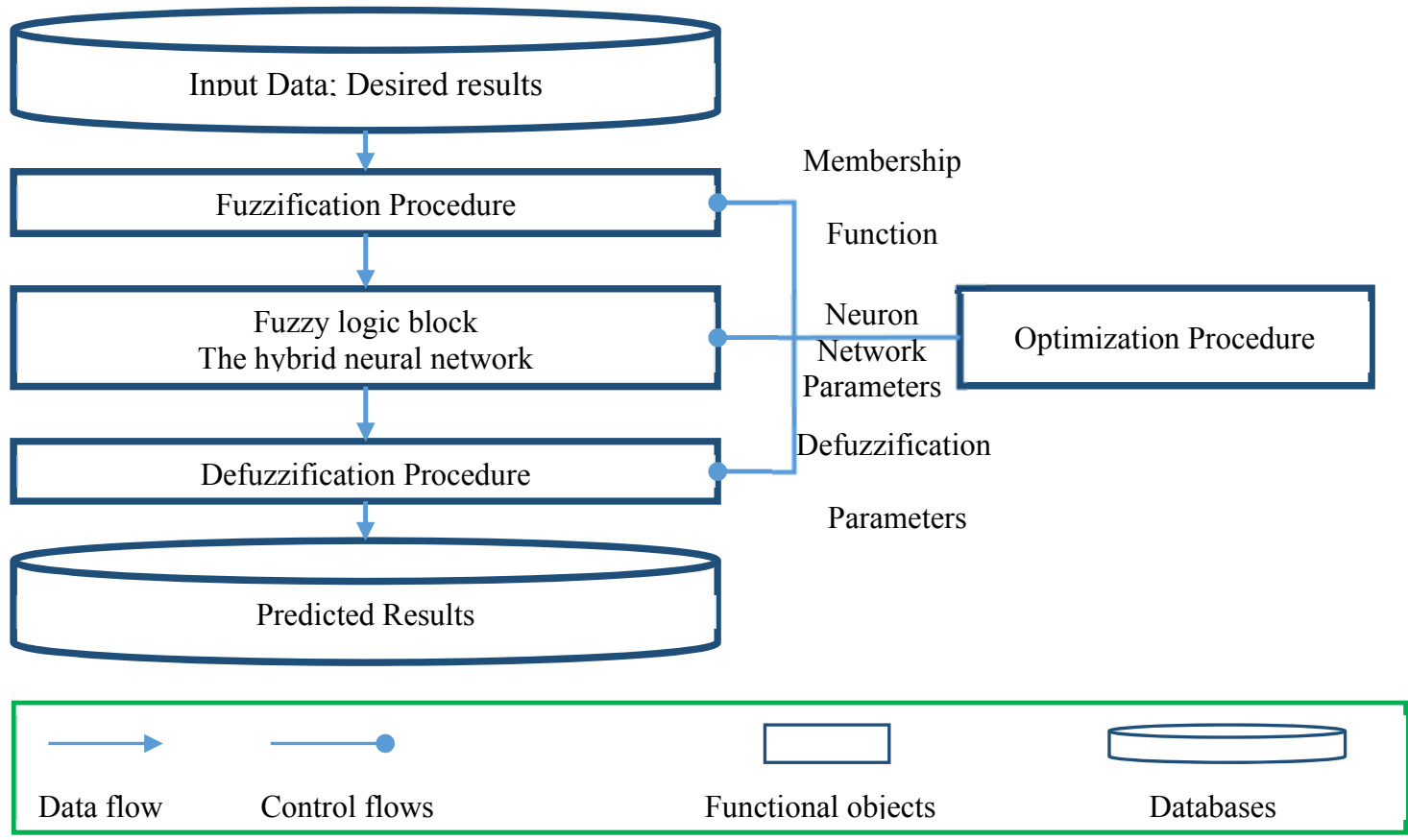

Figure 7. Architecture of the management and control systems 
To conduct researches on the basis of fuzzy modeling, quite versatile software have been developed that greatly simplify the creation of new control systems using neural networks and fuzzy models. The use of different aspects of evolutionary modeling as a new direction of computing technology allows applying principles of learning for the management and control system and adaptation of the described hybrid neural network allows getting the following results.

\section{CONCLUSIONS AND RESULTS}

Automatic control function of blade positions precisely adjusts the cutting edge. Depending on the content of correction signals, the regulating dual hydraulic valve automatically lifts or drops the cutting edge of the blade, constantly keeps it in position that ensures the accuracy of work and ensures an optimum level of productivity.

Identification technique of the dozer's working processes and models obtained on its base, are intended to be used in the development of adaptive systems of automatic control of the dozer's working process.

Methods of development of adaptive systems of control of the dozer's working process, is based on neural network technology. For the formation of control actions on a dozer, and of the electrical switch signals of the hydraulic directional valves of the lifting and dropping hydraulic cylinders of the working body, in particular, the structure and functioning algorithms of the adaptive neural network controller have been designed.

Use of the presented approach can be used not only for earthmoving machinery, but also for the machinery does not require high speed of movement, but dependent of resistance on work body, such as agromachinery.

\section{REFERENCES}

[1] Krapivin D.M., Nefedov V.V., Tokmakov G.E. Mathematical model for the movement of mechatronischen devices for the intelligent building site, Mechatronik, Lik, Nowotscherkassk, 2010.- S. 50-54.

[2] Bulgakov A.G., Tokmakov G.E. The analysis of the control systems for building site, problems, possible solutions. VII Internationally scientific conferences: Realisation of the European scientists; 17th-25th of July, 2011. Sofia. S. 43-44.

[3] Shestopalov K.K., Hoisting-and-transport, building and road machines and equipment. M .: Academy, 2009. P. 67-72.

[4] Bulgakow A.G., Jehle P.,Tokmakov G. SCMlogistic and mechatronics systems for ensuring the smooth construction process // Innovation in Mechanical Engineering - Shaping the Future: 56-th
International Scientific Colloquium (12-16 September 2011: Conference Proceedings /Ilmenau University of Technology).Ilmenau, 2011.

[5] Hughes S.W., Tippett D.D., Thomas W.K. Measuring project success in the construction industry // EMJ - Engineering Management Journal. 2004. 16(3). P. 31-37.

[6] Min-Yuan Cheng, Hsing-Chih Tsai, Erick Sudjono. Evolutionary fuzzy hybrid neural network for construction industry. Automation in Construction 21 (2012) S. 46-51.

[7] Meshcheryakov V.A., Identification of earthmoving machines as a dynamic objects based on neural network technology // Problems of development and operation of vehicles, special machinery and technology in Siberia and the Far North. Proceedings 43 th International Scientific Conference of the Association of Automotive Engineers. - Omsk: Publishing House of the "LEO", 2004. - S. 176.

[8] Denisov V.P., Automatic speed control system for grader // Building and road machines. - 2003.- № 5.pp 39-41.

[9] Weber V.V. Dynamic analysis grader equipment on base of CAD / CAE technology // Interuniversity collection of works of young scientists and students. Omsk: SibADI, 2004. - Vol. 1, Part 1. - pp. 141-146. [10] Kruglov V.V., Borisov V.V., Neural networks. Theory and practice. M: Hotline Telecom 2002.

[11] Gorban A.N., Dunin-Barkovskii V.L., Kirdina A.N., Neuroinformatics / Novosibirsk: Nauka, 1998.

[12] Gorban A.N., Russiev D.A., Neural networks on personal computer. Novosibirsk: Nauka, 1996.

[13] Kureychik V.M. Genetic algorithms. State problems, prospects., Izvestiya RAN, Theory and control system., 1999. № 1. C. 144-160.

[14] Rutkovskij L., Pilinskij M. Neural networks, genetic algorithms and fuzzy systems., Gorzachaza Liniza TELEKOM, 2004.

[15] M.E. Georgy, L.M. Chang, L. Zhang, Prediction of engineering performance: a neurofuzzy approach, Journal of Construction Engineering and Management 131 (5) (2005) 548-557

[16] Mecheryakov V.A. Recurrent algorithm neural identification working process earthmoving machinery. Siberian State Automobile and Highway Academy, Omsk, 2007.- S. 63-66

[17] Leonenkov A.V., Fuzzy modeling in MATLAB environment and fuzzyTECH. SPb .: BHV - St. Petersburg, 2003. 736 p.

[18] T.M. Cheng, C.W. Feng, M.Y. Hsu, An integrated modeling mechanism foroptimizing the simulation model of construction operation, Autom. Constr. 15 (2006) 327-340. 
